\title{
AGROMETEOROLOGIA
}

\section{TEMPERATURA DO AR EM SISTEMAS DE PRODUÇÃO DE CAFÉ ARÁBICA EM MONOCULTIVO E ARBORIZADOS COM SERINGUEIRA E COQUEIRO-ANÃO NA REGIÃO DE MOCOCA, SP (1)}

\author{
LUIS SÉRGIO DE PAIVA VALENTINI ( $\left.{ }^{2}\right)$; MARCELO BENTO PAES DE CAMARGO $\left({ }^{*}, 6\right)$; \\ GLAUCO DE SOUZA ROLIM $\left({ }^{3}\right)$; PAULO SÉRGIO SOUZA $\left({ }^{4}\right)$ PAULO BOLLER GALLO $\left({ }^{4}\right)$
}

\begin{abstract}
RESUMO
A técnica de cultivos consorciados ou arborizados de cafezais visa atenuar as adversidades meteorológicas extremas podendo contribuir para o desenvolvimento do cultivo. O trabalho teve como objetivo caracterizar a temperatura do ar em sistemas de arborização de cafeeiros, comparado com o plantio a pleno sol. Foram realizadas avaliações em experimento de campo, implantado em 1999, no município de Mococa, representativo de uma das mais importantes regiões produtoras de café do Estado de São Paulo. As mensurações de temperatura foram realizadas durante os anos de 2006/2007 e 2007/2008. As parcelas experimentais possuiam $1600 \mathrm{~m}^{2}$, onde foram avaliados cafeeiros (Coffea arabica L.) cv. Icatu Vermelho IAC 4045, cultivados a pleno sol e em sistemas arborizados com seringueira $(16 \times 16 \mathrm{~m})$ e coqueiro-anão $(8 \times 8 \mathrm{~m})$. O tratamento com arborização com seringueira foi o que resultou em melhor desenvolvimento, reduzindo as temperaturas máximas diárias em até $3{ }^{\circ} \mathrm{C}$, especialmente durante o verão e a primavera. Em dias mais amenos, os resultados foram semelhantes entre os tratamentos arborizados com seringueira e coqueiro. Maiores valores de amplitude térmica foram observados no talhão de café a pleno sol. O sistema de arborização minimiza os efeitos de fortes resfriamentos já que o tratamentos arborizados elevaram a temperatura mínima do ar em até $2^{\circ} \mathrm{C}$.
\end{abstract}

Palavras-chave: microclima, Coffea arabica, arborização, geada, sistema agroflorestal.

\section{ABSTRACT \\ AIR TEMPERATURE IN UNSHADED ARABIC COFFEE SYSTEMS AND ARBORIZED WITH RUBBER TREE AND DWARF COCONUT PALM AT MOCOCA REGION, STATE OF SÃO PAULO, BRAZIL}

The technique of arborized coffee crops attemp to minimize the extreme meteorological conditions improving the crop development and yield. This work aimed to characterize the air temperature in arborized systems compared to unshaded cultivation. Evaluations were accomplished in a field experiment, implanted in 1999 at Mococa, one of the most important coffee producing areas at State of São Paulo, Brazil. The experimental plot had $1600 \mathrm{~m}^{2}$, where the coffee plants, cv. Icatu Vermelho IAC 4045, were cultivated in unshaded and arborized systems with rubber tree $(16 \times 16 \mathrm{~m})$ and dwarf coconut palm $(8 \mathrm{X} 8 \mathrm{~m})$. The air temperature measurements were made during 2006/ 07 and 2007 / 08 crop production years. The treatment with rubber tree reduced the daily maximum air temperature up to $3{ }^{\circ} \mathrm{C}$, especially during summer and spring seasons. In cloudy days there were no differences among treatments with rubber tree and dwarf coconut palm tree and unshaded system. Higher values of daily air temperature amplitude were observed in unshaded coffee treatment. The arborized systems minimize the extreme low temperature effect as they raise the minimum air temperature up to $2{ }^{\circ} \mathrm{C}$.

Key words: microclimate, Coffea arabica, production system, shaded, frost.

(1) Recebido para publicação em 24 de junho de 2009 e aceito em $1 .^{\circ}$ de março de 2010.

( ${ }^{2}$ Aluno de Mestrado no Curso de Agricultura Tropical e Subtropical, área de Concentração Tecnologia da Produção Agrícola, IAC/ APTA, Caixa Postal 28, 13001-970 Campinas (SP). E-mail: lsvalentini@ig.com.br

$\left({ }^{3}\right)$ Centro de Pesquisa e Desenvolvimento de Ecofisiologia e Biofísica, Instituto Agronômico, Caixa Postal 28, 13001-970 Campinas (SP). E-mail: mcamargo@iac.sp.gov.br $\left(^{*}\right)$ Autor correspondente; rolim@iac.sp.gov.br

(4) Polo APTA Nordeste Paulista, Caixa postal 58, 13730-972 Mococa (SP). E-mail: polonordestepaulista@apta.sp.gov.br

$\left.{ }^{(}\right)$Bolsista de produtividade científica CNPq. 


\section{INTRODUÇÃO}

O cafeeiro (Coffea arabica L.) é uma planta originária da Etiópia, onde se desenvolveu sob ambiente de sub-bosques de sombra moderada, indicando ser uma espécie não tolerante a temperaturas extremas. No Brasil, o cultivo do café se desenvolveu extensivamente em ambientes a pleno sol. Estes agrossistemas, predominantes também no Estado de São Paulo, apresentam cultivares selecionadas para alta produtividade em monocultivos com o uso intensivo de insumos, sem mecanismos de autorregulação e equilíbrio.

Entretanto, esse tipo de exploração proporcionou em algumas regiões um caráter nômade da cafeicultura, trazendo como principais problemas a baixa produtividade, lavouras decadentes, alto custo de produção e baixo nível de adoção tecnológica, agravados por condições climáticas adversas, como ocorrência de geadas, secas prolongadas e temperaturas elevadas. Como consequências, podem ser citadas as grandes extensões de solos erodidos e desequilibrados e a ocorrência generalizada de nematóides nas lavouras, propiciando uma cafeicultura marginal e com baixa sustentabilidade. Nessas condições, os problemas nutricionais se tornam críticos, acentuando a bienalidade da produção, prejudicando e levando até a erradicação das lavouras (PeZzopane, 2004).

O mesmo autor afirma que no Brasil, os estudos iniciais em sombreamento de cafezais foram realizados com Inga spp. (Franco e Inforzato, 1951; Carvalho et al., 1961), e desestimularam o uso da técnica, pois os tratamentos proporcionavam níveis muito elevados de sombra e competição entre as espécies. Nessas condições, ocorreu maior diferenciação de gemas vegetativas em relação às gemas reprodutivas, provocando decréscimo na produtividade.

Posteriormente, nas décadas de 70 e 80, a utilização de outras espécies e níveis de sombreamento proporcionou a reutilização dessa técnica, agora denominada arborização, em algumasregiões doBrasil. Na Região Centro-Sul, embora haja predomínio do cultivo de café a pleno sol, a utilização do cultivo arborizado tem aumentado (BAGGIO et al., 1997; CAMARGO, 2008). No Nordeste, durante a década de 80 , a arborização foi prática tradicional e muito utilizada (MATIELlo e FERNANDES, 1989), favorecendo o desenvolvimento vegetativo e a produtividade em longo prazo.

A previsão de aquecimento global emitido pelo Painel Intergovernamental de Mudanças Climáticas (IPCC, 2007) tem causado grande preocupação para o agronegócio do café. Segundo FAZUOLI et al. (2007), o uso da arborização seria uma das técnicas de mitigação para o possível cenário de aquecimento global. Entretanto, são necessários mais estudos microclimáticos para quantificar o efeito dos diferentes tipos de arborização na atenuação das temperaturas máximas e mínimas.

O objetivo deste trabalho foi quantificar as modificações microclimáticas, com ênfase em temperatura do ar em diferentes escalas de tempo, em agrossistemas de cultivo de café consorciados com seringueira e com coqueiro-anão em comparação com sistema de monocultivo.

\section{MATERIAL E MÉTODOS}

Os experimentos em campo foram desenvolvidos em Mococa, em latitude de $21^{\circ} 28^{\prime} \mathrm{S}$, longitude de $47^{\circ} 01^{\prime} \mathrm{W}$, altitude de $665 \mathrm{~m}$. Osolo da área experimental éclassificado como Argissolo Vermelho (OliveIRA et al., 1999). A região possui clima tipo $\mathrm{B}_{1 \mathrm{rB}} 4 \mathrm{a}^{\prime}$ segundo classificação proposta por Thornthwaite, ou seja, mesotérmico úmido, com pequena deficiência hídrica anual de fevereiro a agosto e evapotranspiração potencial acumulada no verão menor que $48 \%$ do total anual (Rolim et al., 2007).

Os diferentes sistemas de arborização testados foram o de café com seringueira e coqueiro-anão, além do tratamento-testemunha sem arborização (pleno sol) (Figura 1). As parcelas experimentais com sete anos de idade, possuíam $40 \times 40$ metros, sendo utilizadas como bordadura as linhas marginais.

Os três sistemas de cultivo foram implantados em de outubro de 1999, nas seguintes configurações: (a) pleno sol (SOL): café arábica Icatu Vermelho IAC4045 enxertado sobre Robusta IAC-Apoatã, plantado com espaçamento de 4 metros entre linhas e 1 metro entre plantas, seguindo o mesmo padrão nos sistemas arborizados. A distribuição da arborização foi feita da seguinte forma: (b) coqueiro-anão (Cocus nucifera L.) (COQ) no espaçamento de $8 \times 8$ metros, totalizando 25 árvores na parcela experimental e (c) seringueira (Hevea brasiliensis) (SER) no espaçamento de 16 x 16 metros, totalizando nove árvores na parcela experimental.

Os dados microclimáticos de temperatura do ar foram coletados nos sistemas cultivados a pleno sol e consorciados continuadamente durante os anos agrícolas de 2006 / 2007 e 2007/ 2008, totalizando 730 dias de análise.

As temperaturas do ar foram determinadas com conjunto psicrométrico, protegidos com abrigos micrometeorológicos, constituídos de doze pratos plásticos sobrepostos, instalados na altura $(2 \mathrm{~m})$ do dossel das plantas de café como sugerido por CARAMORI et al. (1996).

Os sensores foram acoplados a um sistema automático de registro de dados, programado para leituras a cada 20 segundos, cálculo de médias a cada 15 minutos e determinação de valores diários médios e absolutos. A mensuração foi feita na posição central entre quatro plantas utilizadas nas arborizações. 
Diferenças entre tratamentos e estações do ano em relação às temperaturas máximas, mínimas e médias diárias foram determinadas pelo teste $t$ a $5 \%$ de probabilidade. Regressões lineares simples foram utilizadas, com todos os dados, para se observar o efeito dos sistemas arborizados na temperatura do ar.

\section{RESULTADOS E DISCUSSÃO}

\section{Temperatura máxima diária do ar}

Os valores observados demonstram o potencial do sistema de arborização, em comparação com o café a pleno sol, na redução dos valores de temperatura do ar máximos diários (Tmax), tornando o ambiente mais ameno para o cultivo (Tabela 1). O COQ diminuiu a Tmax principalmente na primavera e no verão e SER diminuiu Tmax em todas as estações do ano.
Na primavera (Figura 2a), durante os dias mais quentes e sem nebulosidade, a Tmax de SOL atingiu cerca de $38^{\circ} \mathrm{C}$. Já para os tratamentos arborizados com SER e com COQ as Tmax foram reduzidas em $1,7^{\circ} \mathrm{C}$ e $1,0^{\circ} \mathrm{C}$, respectivamente, em relação ao SOL.

No verão (Figura 2b), as temperaturas máximas de SOL foram mais elevadas $\left(39^{\circ} \mathrm{C}\right)$, enquanto que os tratamentos com SER e COQ, as Tmax foram em média $2,0{ }^{\circ} \mathrm{C}$ e $1,2{ }^{\circ} \mathrm{C}$ inferiores, respectivamente.

Durante o outono (Figura 2c), as Tmax de SOL foram em média de $32,1{ }^{\circ} \mathrm{C}$ e próximas à de $\mathrm{COQ}$, enquanto SER apresentou valor inferior de $1,9^{\circ} \mathrm{C}$ em relação ao SOL.

No inverno (Figura 2d), as temperaturas máximas dos tratamentos foram semelhantes, $29,6{ }^{\circ} \mathrm{C}, 29,5{ }^{\circ} \mathrm{C}$, $30,1^{\circ} \mathrm{C}$, para SOL, SER e COQ, respectivamente.

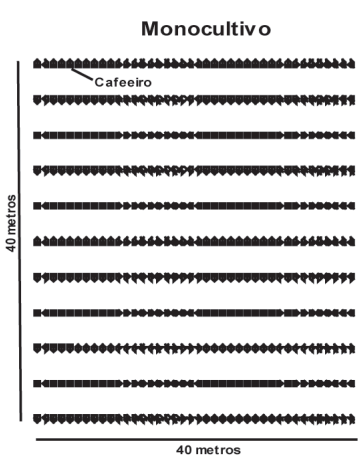

(a)

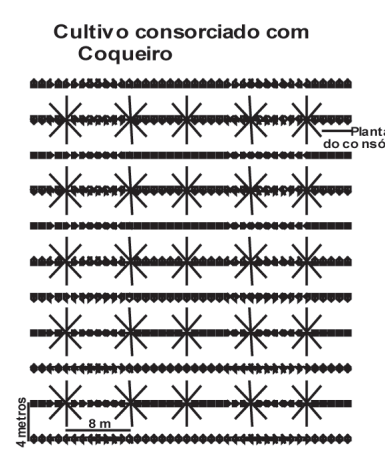

(b)

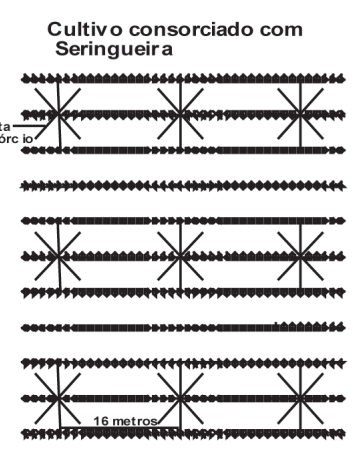

(c)

Figura 1. Representação esquemática das parcelas de café em sistema de monocultivo (a) e consorciado com coqueiro-anão (b) e seringueira (c). Modificado de Pezzopane et al. (2003).

Tabela 1. Média das temperaturas máxima, mínima e média $\left({ }^{\circ} \mathrm{C}\right)$ e valores do teste $\mathrm{t}$ para comparação de médias: graus de liberdade (g.l.), t crítico e probabilidade de ocorrência; em diferentes estações do ano no sistemas de plantio a pleno sol (SOL), arborizado com coqueiro-anão (COQ) e seringueira (SER), para os anos agrícolas de 2006/ 2007 e 2007/ 2008

\begin{tabular}{|c|c|c|c|c|c|c|c|c|c|c|}
\hline \multirow{2}{*}{ Estação } & \multirow{2}{*}{ SOL } & \multicolumn{2}{|c|}{ Arborizado } & \multicolumn{3}{|c|}{ SOL-COQ } & \multicolumn{2}{|c|}{ SOL-SER } & \multicolumn{2}{|c|}{ COQ-SER } \\
\hline & & COQ & SER & g.1. & t crítico & $\operatorname{Pr}>|t|$ & t crítico & $\operatorname{Pr}>|t|$ & t crítico & $\operatorname{Pr}>|t|$ \\
\hline & & \multicolumn{9}{|c|}{ Temperatura Máxima $\left({ }^{\circ} \mathrm{C}\right)$} \\
\hline Primavera & 38,0 & 37,0 & 36,3 & 408 & $5,149 *$ & $<0,0001$ & $6,346^{*}$ & $<0,0001$ & $0,875^{\mathrm{ns}}$ & 0,3818 \\
\hline Verão & 39,0 & 37,8 & 37,0 & 212 & $2,459 *$ & 0,0147 & $3,465 *$ & 0,0006 & $0,753^{\mathrm{ns}}$ & 0,4524 \\
\hline Outono & 32,1 & 31,0 & 30,2 & 289 & $0,295^{\mathrm{ns}}$ & 0,7681 & $6,227 *$ & $<0,0001$ & $5,664 *$ & $<0,0001$ \\
\hline \multirow[t]{2}{*}{ Inverno } & 29,6 & 30,1 & 29,5 & 336 & $-0,226^{\mathrm{ns}}$ & 0,8210 & $3,775^{*}$ & $<0,0001$ & $4,049^{*}$ & $<0,0001$ \\
\hline & & \multicolumn{9}{|c|}{ Temperatura Mínima $\left({ }^{\circ} \mathrm{C}\right)$} \\
\hline Primavera & 17,8 & 17,6 & 17,9 & 408 & $0,751^{\mathrm{ns}}$ & 0,4529 & $-0,213^{\mathrm{ns}}$ & 0,8306 & $-1,009^{\mathrm{ns}}$ & 0,3132 \\
\hline Verão & 19,2 & 19,3 & 19,4 & 212 & $-0,869^{\mathrm{ns}}$ & 0,3854 & $-1,111^{\mathrm{ns}}$ & 0,2679 & $-0,272^{\mathrm{ns}}$ & 0,7854 \\
\hline Outono & 14,7 & 15,6 & 15,4 & 289 & $-2,294 *$ & 0,225 & $-2,294 *$ & 0,0225 & $0,632^{\mathrm{ns}}$ & 0,5275 \\
\hline \multirow[t]{2}{*}{ Inverno } & 13,2 & 13,4 & 13,2 & 336 & $-0,504^{\mathrm{ns}}$ & 0,6142 & $-0,011^{\mathrm{ns}}$ & 0,9908 & $0,512^{\mathrm{ns}}$ & 0,6085 \\
\hline & & \multicolumn{9}{|c|}{ Temperatura Média $\left({ }^{\circ} \mathrm{C}\right)$} \\
\hline Primavera & 23,4 & 22,6 & 22,6 & 408 & $3,486^{*}$ & $<0,0001$ & $3,114 *$ & 0,0019 & $-0,438^{\mathrm{ns}}$ & 0,6615 \\
\hline Verão & 24,1 & 23,9 & 23,8 & 212 & $0,996^{\mathrm{ns}}$ & 0,3200 & $1,218^{\mathrm{ns}}$ & 0,2240 & $0,168^{\mathrm{ns}}$ & 0,8661 \\
\hline Outono & 21,3 & 21,3 & 20,8 & 289 & $1,402^{\mathrm{ns}}$ & 0,1617 & $1,402^{\mathrm{ns}}$ & 0,1617 & $1,691^{\mathrm{ns}}$ & 0,0917 \\
\hline Inverno & 20,5 & 20,5 & 20,0 & 336 & $0,261^{\mathrm{ns}}$ & 0,7945 & $1,521^{\mathrm{ns}}$ & 0,1292 & $1,291^{\mathrm{ns}}$ & 0,1977 \\
\hline
\end{tabular}

ns: não significativo. * significativo a $5 \%$ de probabilidade. 

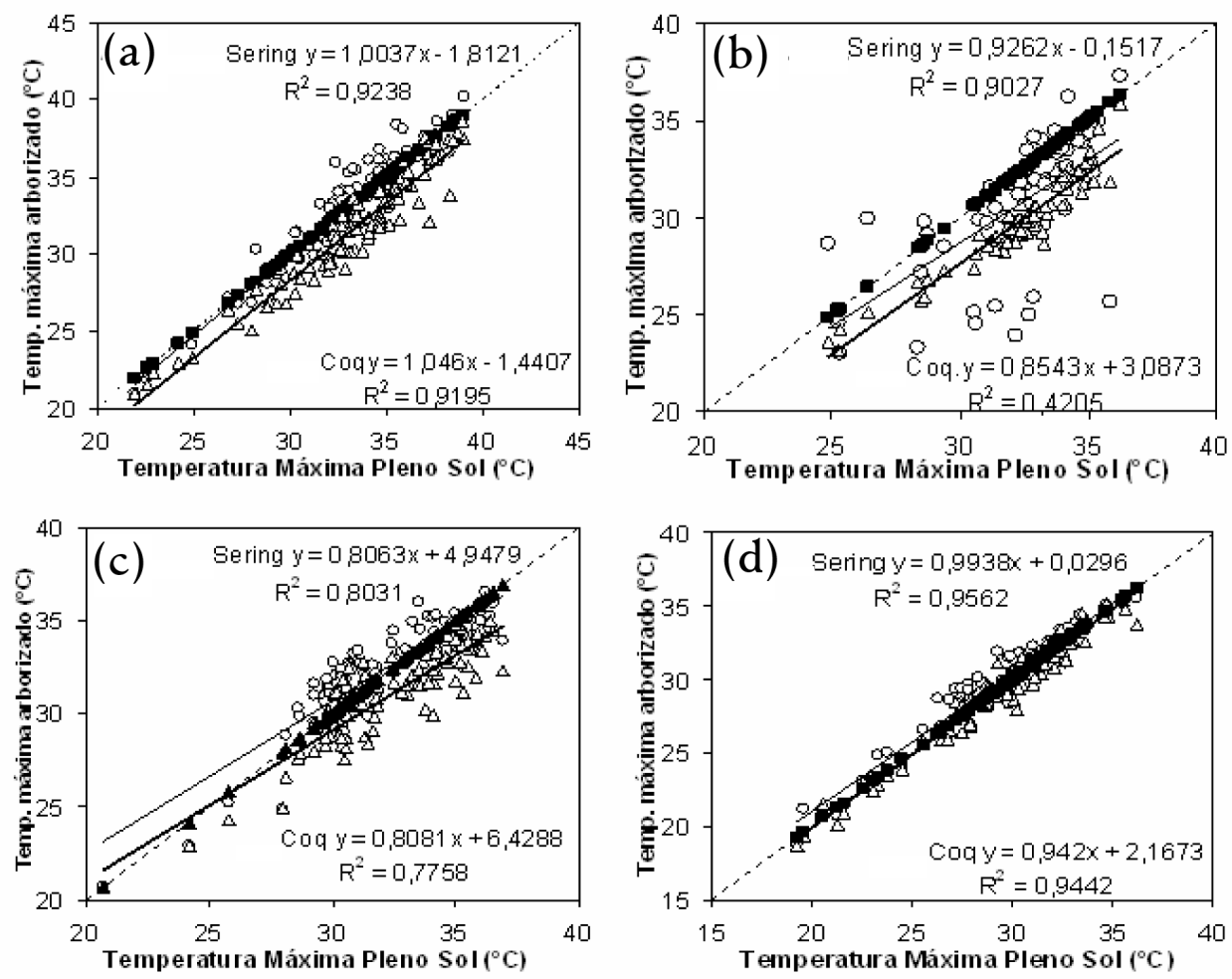

Figura 2. Relação da temperatura máxima diária observada no tratamento a pleno sol e nos arborizados com coqueiro-anão e seringueira nas estações do ano: (a) Primavera, (b) Verão, (c) Outono e (d) Inverno, mensurados na posição central da parcela experimental. Seringueira $(\Delta)$, coqueiro-anão $(o)$, pleno sol (ם).
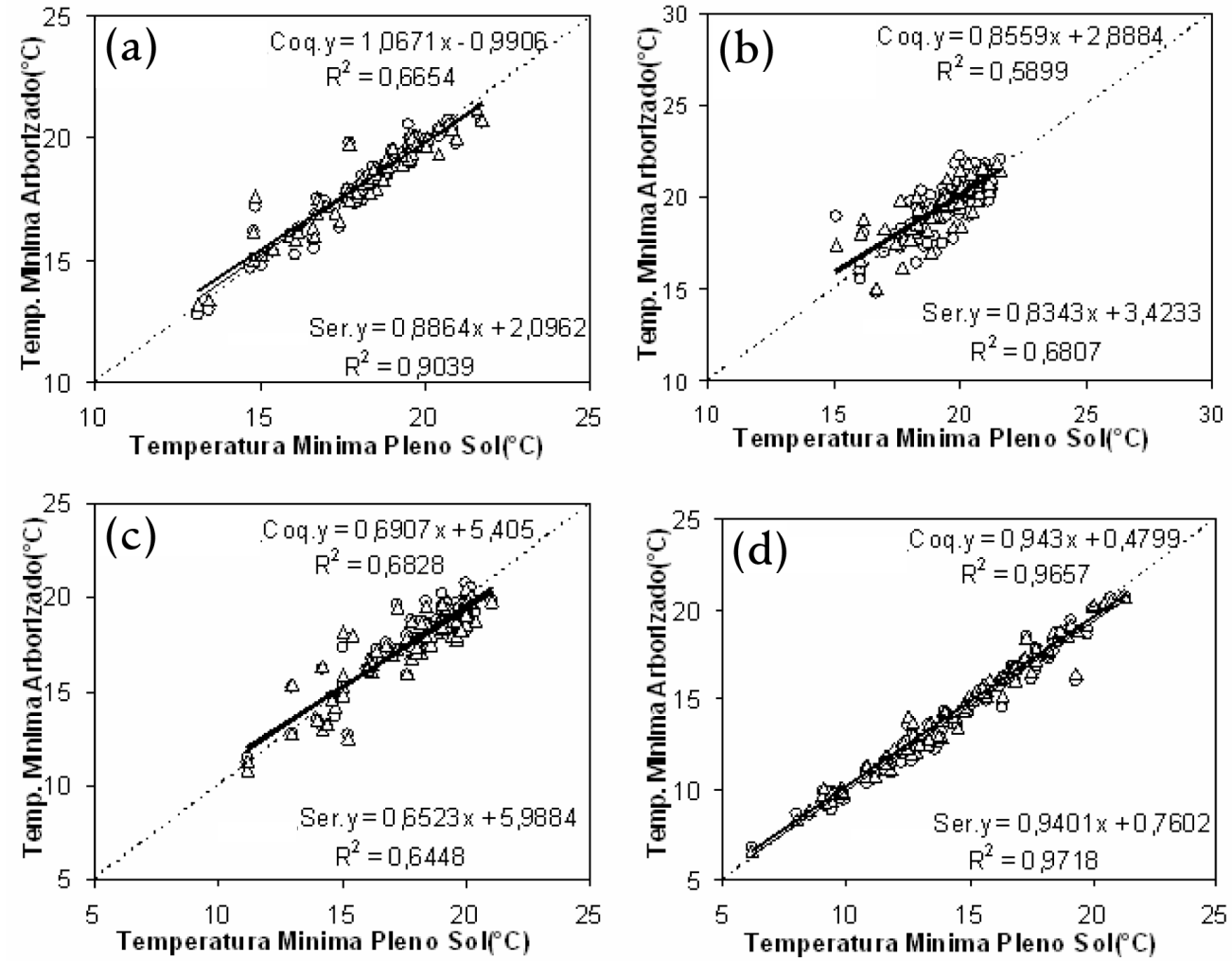

Figura 3. Relação da temperatura do ar mínima diária observada no tratamento a pleno sol e nos arborizados com coqueiro-anão e seringueira nas estações do ano: (a) Primavera, (b) Verão, (c) Outono e (d) Inverno, mensurados na posição central da parcela experimental. seringueira $(\Delta)$, coqueiro-anão $(o)$, pleno sol (ם). 

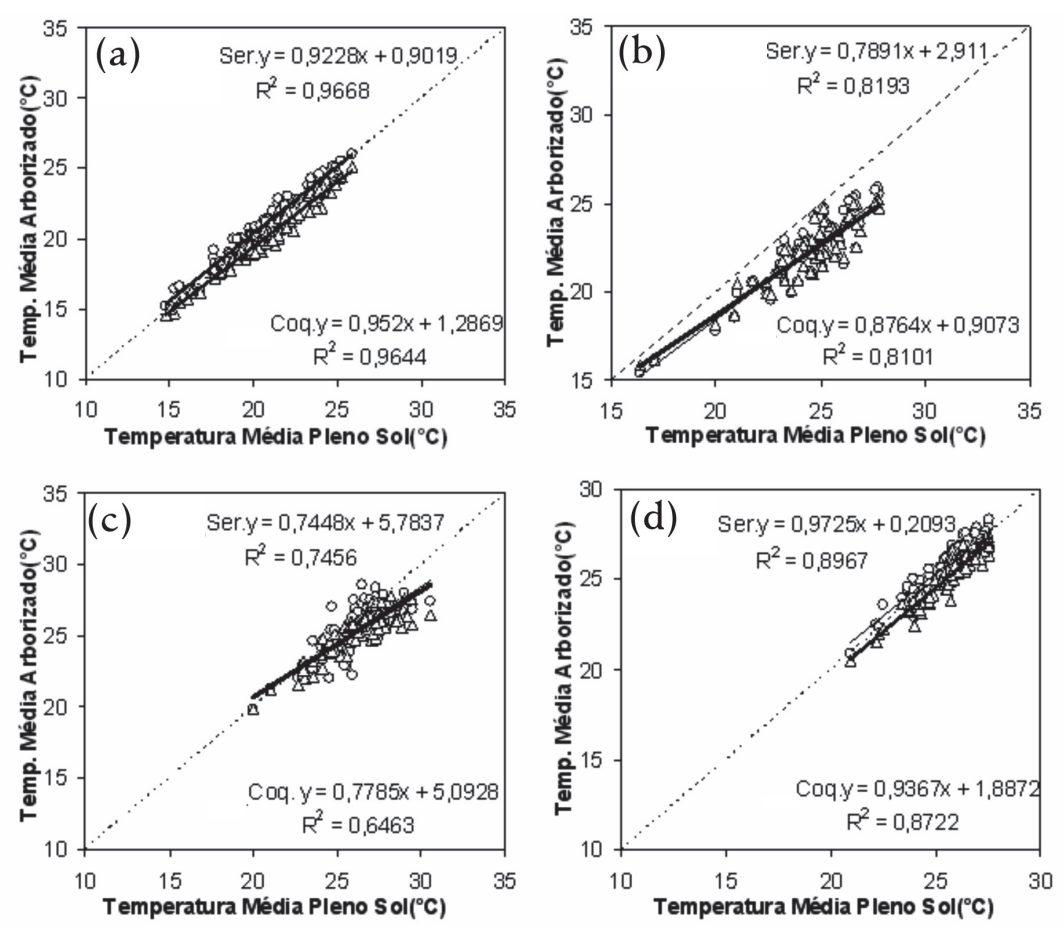

Figura 4. Relação da temperatura média diária observada no tratamento a pleno sol e nos arborizados com coqueiro-anão e seringueira nas estações do ano: (a) Primavera, (b) Verão, (c) Outono e (d) Inverno, mensurados na posição central da parcela experimental. Seringueira $(\Delta)$, coqueiro-anão (o), pleno sol (ם).

Analisando os resultados de cada estação do ano, os tratamentos com arborização demonstraram ser eficientes para diminuir a Tmax em até $3{ }^{\circ} \mathrm{C}$, principalmente nos dias quentes com céu sem nebulosidade da primavera e verão que correspondem aos estádios fenológicos críticos da floração e frutificação, respectivamente (CAmargo e CAmargo, 2001). Estes resultados estão de acordo os relatados por CRUZ (2003) em ambientes com temperaturas elevadas e deficiência hídrica, onde o sistema de arborização se constitui em uma técnica eficaz para melhorar as condições de cultivo. BARRADAS e FANJUL (1986) também obtiveram resultados semelhantes em plantios no México. Esses autores observaram que em plantios a pleno sol as temperaturas máximas diárias foram sempre superiores aos arborizados.

Sabe-se que o tipo e densidade da vegetação que cobre o solo interferem no microclima (SHAW e PEREIRA, 1982). O efeito conjunto do tipo de copa e do espaçamento foi observado pelo teste $\mathrm{t}$ ( $5 \%$ de probabilidade) na comparação entre COQ e SER (Tabela 1) em todo o período analisado. Observou-se que a temperatura máxima média foi significativamente diferente somente no outono e inverno.

\section{Temperatura mínima diária do ar}

Os resultados em relação à temperatura mínima média $\left({ }^{\circ} \mathrm{C}\right)($ Tmin) no município de Mococa demonstram pouco potencial dos tratamentos COQ e SER, em comparação com SOL, no aumento dos valores de Tmin em todas as estações do ano (Figura 3) na região de Mococa, SP. A análise com valores médios indicou que somente no outono o aumento da Tmin se torna significativa em todos os tratamentos (Tabela 1). Apesar disso, observa-se uma pequena tendência de aumento da Tmin em dias mais frios nos sistemas arborizados em todas as estações (Figura 3).

Os resultados de BarRadas e FAnJul (1986), Miguel et al. (1995), Pezzopane et al. (2003; 2007) evidenciam que os efeitos nas temperaturas mínimas diárias dependem do clima do local, do tipo de copa da árvore e da densidade do sombreamento utilizados. CARAMORI et al. (1996), BAGgio et al. (1997) e CARAMORI e Morais (1999) ainda demonstram que sistemas arborizados podem promover proteção aos cafeeiros em noites de geadas.

Não se observou diferenças significativas na Tmin entre os tratamentos COQ e SER indicando que o tipo de planta utilizada para arborização e o espaçamento utilizado são equivalentes na região (Tabela 1).

\section{Temperatura média do ar}

A análise dos valores da temperatura média do ar (Tmed) indica diferenças significativas somente na primavera (Tabela 1). Entretanto, observou-se uma diminuição de Tmed nos dias mais quentes do verão (Figura $4 \mathrm{~b}$ ) e no outono (Figura 4c) em até $3{ }^{\circ} \mathrm{C}$ e $2{ }^{\circ} \mathrm{C}$ respectivamente. 
Devido ao grande efeito de diminuição das Tmax durante a primavera e o verão, a amplitude térmica nos sistemas arborizados foi sempre menor em relação à SOL. Por exemplo, durante a primavera as amplitudes térmicas médias registradas foram $20,2{ }^{\circ} \mathrm{C} ; 19,4{ }^{\circ} \mathrm{C} ; 18,4$ ${ }^{\circ} \mathrm{C}$ para SOL, COQ e SER respectivamente (Tabela 1).

\section{CONCLUSÕES}

1. Os tratamentos arborizados promovem a diminuição da amplitude térmica em todas as épocas do ano, aumentando a temperatura mínima, principalmente em dias mais frios de outono e reduzindo a temperatura máxima.

2. O tratamento de arborização com seringueiraé de melhor desempenho para reduzir a temperatura máxima em até $3{ }^{\circ} \mathrm{C}$ durante os dias mais quentes, especialmente durante a primavera e verão que correspondem aos estádios fenológicos críticos da floração e da frutificação.

3. A arborização reduz a temperatura média diária em dias quentes do verão e outono.

\section{AGRADECIMENTOS}

À FAPESP pelo financiamento ao projeto.

\section{REFERÊNCIAS}

BAGGIO, A.J.; CARAMORI, P.H.; ANDROCIOLI, A.; MONTOYA, L. Productiviy of southern Brazilian coffee plantations shaded by different stockings of Grevillea robusta. Agroforestry systems, v. 37, p.111-120, 1997.

BARRADAS, V.L.; FANJUL, L. Microclimatic characterization ofshaded and open-grown coffee (Coffea arabica L.) plantations in Mexico. Agricultural and Forest Meteorology, v.38, p.101112, 1986.

CAMARGO, A.P.; CAMARGO, M.B.P. Definição e esquematização das fases fenológicas do cafeeiro arábica nas condições tropicais do Brasil. Bragantia, v.60, p.65-68, 2001.

CAMARGO, M.B.P. The impact of climatic variability on the coffee crop In: International Conference on Coffee Science, 22., 2008, Campinas, SP, Brazil. Resumos... Lausanne, Switzerland: Association for Science and Information on Coffee - ASIC, 2008, v.22, p.62-66.

CARAMORI, P.H.; ANDROCIOLI FILHO, A.; LEAL, A.C. Coffee shade with Mimosa scabrella Benth for frost protection in southern Brazil. Agroforestry Systems, v.33, p.205-214, 1996.

CARAMORI, P.H.; MORAIS, H. Proteção de cafezais recémimplantados contra geada através do plantio intercalar de espécies anuais. In: Congresso Brasileiro de Pesquisas Cafeeiras, 25., Franca, 1999. Trabalhos apresentados... Rio de Janeiro: PROCAFE, 1999. p.111-112.
CARVALHO, A.; KRUG, C.A.; MENDES, J.E.T.; ANTUNES FILHO, H.; JUNQUEIRA, A.R.; ALOISI SOBRINHO, J.; ROCHA, T.R.; MORAES, M.V. Melhoramento do cafeeiro. XXI - Comportamento regional de variedades, linhagens e progênies de café ao sol e à sombra. Bragantia, v.20, p.10451142, 1961.

CRUZ, R.F.R. Efeito da arborização com guandu na primeira produção de café no norte do Paraná. In: Simpósio de Pesquisa dos Cafés do Brasil e Workshop Internacional de Café \& Saúde, 3., 2003, Porto Seguro. Resumos... Brasília, DF: Embrapa Café, 2003. p. 286.

FAZUOLI, L.C.; THOMAZIELLO, R.A.; CAMARGO, M.B.P. Aquecimento global, mudanças climáticas e a cafeicultura paulista. O Agronômico, v.59, p. 19-20, 2007.

FRANCO, C.M.; INFORZATO, R. Quantidade de água transpirada pelo cafeeiro sombreado e pelo ingazeiro. Bragantia, v.11, p.121-125, 1951.

MATIELLO, J.B.; FERNANDES, D.R. Observações sobre arborização de cafezais em regiões de Chapada na Bahia. In: Congresso Brasileiro de Pesquisas Cafeeiras, 15., Maringá. Anais... Rio de Janeiro, RJ: IBC, 1989. p.238-240.

MIGUEL, A.E.; MATIELLO, J.B.; CAMARGO, A.P.; ALMEIDA, S.R.; GUIMARÃES, S.R. Efeitos da arborização do cafezal com grevílea robusta nas temperaturas do ar e umidade do solo, Parte II. In: CONGRESSO BRASILEIRO DE PESQUISAS CAFEEIRAS, 21., Rio de Janeiro.Trabalhos apresentados... Rio de Janeiro, RJ: PROCAFE, 1995. p.1-12.

OLIVEIRA, J.B.; CAMARGO, M.N.; ROSSI, M; CALDERANO FILHO, B. Mapa pedológico do Estado de São Paulo: Legenda expandida. Campinas: Instituto Agronômico/Embrapa Solos, 1999. 64p.

PEZZOPANE, J.R.M. Avaliações microclimáticas, fenológicas e agronômicas em café arábica cultivado a pleno sol e consorciado com banana 'Prata Anã'. 2004. 136f. Tese (Doutorado em Agronomia)- Escola Superior de Agricultura 'Luiz de Queiroz', Universidade de São Paulo, Piracicaba.

PEZZOPANE, J.R.M.; GALLO, P.B.; PEDRO JÚNIOR, M.J.; ORTOLANI, A.A. Caracterização microclimática em cultivo consorciado café/ coqueiro anão verde. Revista Brasileira de Agrometeorologia, v.11, p.293-302, 2003.

PEZZOPANE, J.R.M.; PEDRO JÚNIOR, M.J.; GALLO, P.B.; CAMARGO, M.B.P.; FAZUOLI, L.C. Avaliações fenológicas e agronômicas em café arábica cultivado a pleno sol e consorciado com banana 'Prata Anã'. Bragantia, v.66, p.701709, 2007.

ROLIM, G.S.; CAMARGO, M.B.P.; LANIA, D.G.; MORAES, J.F.L. Classificação climática de Köppen e de Thornthwaite e sua aplicabilidade na determinação de zonas agroclimáticas para o Estado de São Paulo. Bragantia, v.66, p.711-720, 2007.

SHAW, R.H.; PEREIRA, A.R. Aerodynamic roughness of a plant canopy: a numerical experiment. Agricultural Meteorology, v.26, p.51-65, 1982. 